\title{
Lysosomal Enzymes in Experimental Allergic Encephalomyelitis: Time Course and Evidence of the Source
}

\author{
Luca Massacesi, ${ }^{1}$ Anna Laura Abbamondi, ${ }^{1}$ Laura Raimondi, ${ }^{2}$ Carla Giorgi, ${ }^{1}$ and Luigi \\ Amaducci $^{1}$
}

(Accepted June 12, 1987)

\begin{abstract}
The lysosomal enzymes acid proteinase and $\beta$-glucuronidase, were assayed in spinal cords of rats during the course of experimental allergic encephalomyelitis (EAE). Histological and histochemical examination was carried out versus controls, in selected areas of the same cords biochemically assayed, to look at the distribution of the lysosomal enzyme acid phosphatase. The biochemical assay showed a significant increase of the enzyme activities during the disease and the increase was significantly correlated with the intensity of the disease. The distribution in the nervous tissue of the increase in acid phosphatase activity observed in animals with EAE, suggests that endogenous nervous cells may contribute to the lysosomal enzyme increase in EAE.
\end{abstract}

KEY WORDS: Experimental allergic encephalomyelitis; acid proteinase; $\beta$-glucuronidase; acid phosphatase.

\section{INTRODUCTION}

In past years inflammatory cells of hematogenous origin were proposed as the principal source of spinal cord lysosomal enzyme increase in experimental allergic encephalomyelitis (EAE) $(1,2)$. On this line, the assay of acid proteinase (cathepsin D) activity has been suggested for quantification of the spinal cord perivascular infiltrates $(3,4)$. Although elevated levels of lysosomal enzymes in EAE is a well established observation $(1,2,5)$, there remain a number of critical questions concerning their source and role in the demyelinating process. The biochemical study of whole nervous tissue can not discriminate the contribution of inflammatory cells to the enzyme activity increase, from that attributable to the endogenous glial and neuronal cells. In order to assess the temporal and space relation

${ }^{1}$ Department of Neurology and ${ }^{2}$ Department of Pharmacology, University of Florence, Viale Morgagni 85, 50134, Florence, Italy. between the increase of lysosomal enzymes and perivascular infiltrates in spinal cord, the enzyme activity in the whole tissue can be biochemically assayed contemporary to the examination of the anatomical distribution of lysosomes, histochemically evaluated through a lysosomal marker enzyme.

In this communication, the time course of two lysosomal hydrolase activities, acid proteinase and $\beta$-glucuronidase, has been assayed in spinal cord of rats during the development of acute EAE, in respect to the histological and histochemical evaluation of inflammatory infiltrates and acid phosphatase activity.

\section{EXPERIMENTAL PROCEDURE}

Induction of EAE. EAE was induced in 38 Lewis rats (175225 grams, Charles Rivers) through immunization with $1 \mathrm{mg}$ of guinea pig lyophylized myelin, in $0.5 \mathrm{ml}$ complete Freund's adjuvant containing $3 \mathrm{mg} / \mathrm{ml}$ of Mycobacterium Tuberculosis (CFA). The mixture emulsified in saline solution, was injected 
subcutaneously in both hind foot pads. Control rats (29) were injected with $0.5 \mathrm{ml}$ CFA only.

The animals were followed every other day and from day 8 daily, for weight and clinical symptoms. In the described model, the disease begins about day 12 after immunization. For the laboratory examination were chosen four critical days during the course of EAE, one just before the expected onset of the disease (day 8), one immediately before and at the expected onset of the disease (day 11 and 12) and one immediately after (day 14). About day 12 , weight loss and variable degree of neurological symptoms could be observed in the immunized rats. The severity of the symptoms was graded on a scale of 1 to 5 as follows: 0 , no symptoms; 1 , tail paralysis; 2 , tail paralysis and weakness of the hind legs; 3 , hind legs paralysis; 4 , tetraplegia; 5 , death.

Preparation of Tissue. The animals were anesthetized with ether and sacrificed through cardiac exsanguination. Spinal cords were dissected and the lumbar extremities (approximately $\frac{1}{4}$ of the total), were fixed in buffered formalin or frozen in liquid nitrogen for histological and histochemical examination respectively. The remaining spinal cord was homogenized in 20 volumes $(w / v) 0.25 M$ sucrose for the enzyme assays. For protein estimation $50 \mu \mathrm{l}$ of each sample were diluted to $5 \mathrm{ml} 0.1 \mathrm{M} \mathrm{NaOH}$.

Acid proteinase (APr) Determination. $0.2 \mathrm{ml}$ of the $5 \%$ homogenate was assayed as previously described (6) using hemoglobin as substrate.

$\beta$-glucuronidase ( $\beta-G l)$ Determination. The $5 \%$ homogenate was assayed by modification of the method described by Fishman (7) using phenolphthaleinglucuronide as substrate. The incubation mixture consisted of $0.1 \mathrm{ml}$ of the homogenate containing $0.1 \%$ Triton $\mathrm{X}-100,0.3 \mathrm{ml} 0.04 \mathrm{M}$ buffer acetate $\mathrm{pH} 5.2$ and 0.1 $\mathrm{ml} \mathrm{H}_{2} \mathrm{O}$ containing $0.68 \mathrm{mg}$ phenolphthaleinglucuronide (Calbiochem). After 2 hours incubation at $37^{\circ}$, the reaction was stopped by the addiction of $2 \mathrm{ml} 0.2 \mathrm{M}$ glycine buffer $\mathrm{pH} 10.2$.

Protein Analysis. Estimation of the protein content of an aliquot of the homogenate was performed by the method of Lowry et al. (8).

Histological and Histochemical Examination. The caudal part of the lumbar extremities was fixed in buffered formalin, cut into paraffin embedded $8 \mu \mathrm{m}$ sections, stained with haematoxylin and eosin and examined for the presence of perivascular cuffs. The cranial part was snap frozen in liquid nitrogen, sections cut at $6-8 \mu \mathrm{m}$ were air dried, placed in the incubation solution containing the substrate for acid phosphatase as previously described (9) and counterstained with haematoxylin to show cell morphology. The increase of positive reaction was examined versus controls in and around perivascular cuffs. All sections were examined by two examiners not informed of the treatment protocol.

\section{RESULTS}

All immunized rats developed EAE about day 12 after immunization (Table I, Figure 1).

The APr and $\beta-G l$ specific activity increased durring the course of the disease showing a significant positive correlation $(p<0.001)$ with the time and with the neurological symptoms (Table II, Figures 2 and 3). The increase of the two enzymes were significantly correlated $(p<0.001$, Figure 4$)$. At day
Table 1. Time Course of EAE Symptoms and Spinal Cord Histological and Histochemical Findings

\begin{tabular}{|c|c|c|c|c|}
\hline $\begin{array}{l}\text { Day after } \\
\text { injection }\end{array}$ & 8 & 11 & 12 & 14 \\
\hline $\begin{array}{c}\text { Neurological } \\
\text { symptoms }\end{array}$ & $\begin{array}{l}0 / 38 \\
(0)\end{array}$ & $\begin{array}{c}21 / 34 \\
(1.3 \pm 0.9)\end{array}$ & $\begin{array}{c}21 / 23 \\
(2.6 \pm 0.6)\end{array}$ & $\begin{array}{c}7 / 7 \\
(3.7 \pm 0.7)\end{array}$ \\
\hline $\begin{array}{l}\text { Perivascular } \\
\text { cuffs }\end{array}$ & $0 / 4$ & $6 / 11$ & $16 / 16$ & $7 / 7$ \\
\hline APA & $0 / 4$ & $6 / 11$ & $16 / 16$ & $7 / 7$ \\
\hline
\end{tabular}

The ratio represent the number of rats that developed any symptom, perivascular cuff or APA increase, in respect to the number of rats tested each day. The APA represents the increase versus the controls of acid phosphatase activity outside the infiltrates, evidenced through counterstain of the section with hematoxolin. In parenthesis are reported the neurological symptom mean scores $\pm \mathrm{SD}$.

8, 3-4 days before the onset of the disease, the APr and $\beta-G 1$ specific activity was still at the level of the Freund's adjuvant injected control rats. The increase of the two enzymes was significant versus the controls beginning from day $11(\mathrm{p}<0.01$ and $\mathrm{p}$ $<0.005$, respectively). Further increments were observed at day 12 and $14(\mathrm{p}<0.001)$ (Table II). At these days APr show a peak reaching levels higher than $\beta$-Glu (Table II, Figures 2 and 3).

Histological and histochemical examination of spinal cord showed the acid phosphatase activity (APA) increased in respect to the samples from the control rats (Figure 5). The APA increment involved the area of perivascular cuffs and the nervous tissue

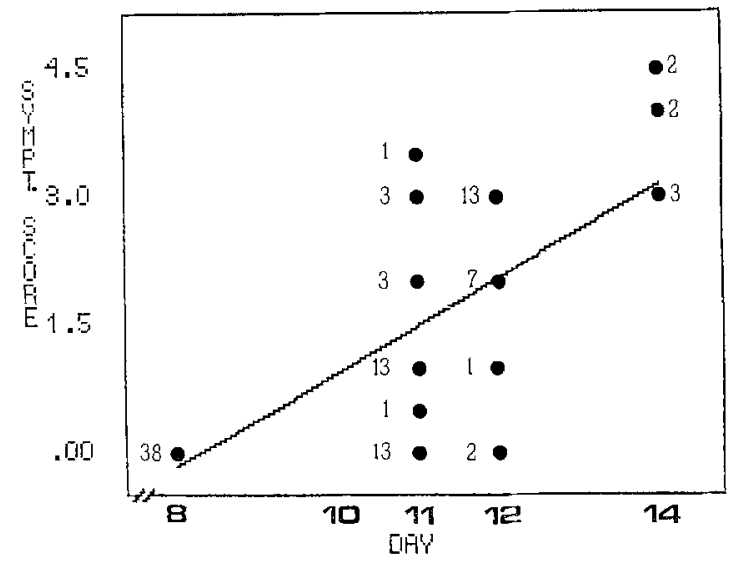

Fig. 1. Neurological symptom scores observed in each immunized rat at the days chosen for the laboratory examinations. The numbers represent the number of observations contributing to each point. For the score see the section Materials and Methods. The line represents the linear regression of the symptoms on the days $(r=0.783 ; \mathrm{p}<0.001)$. 

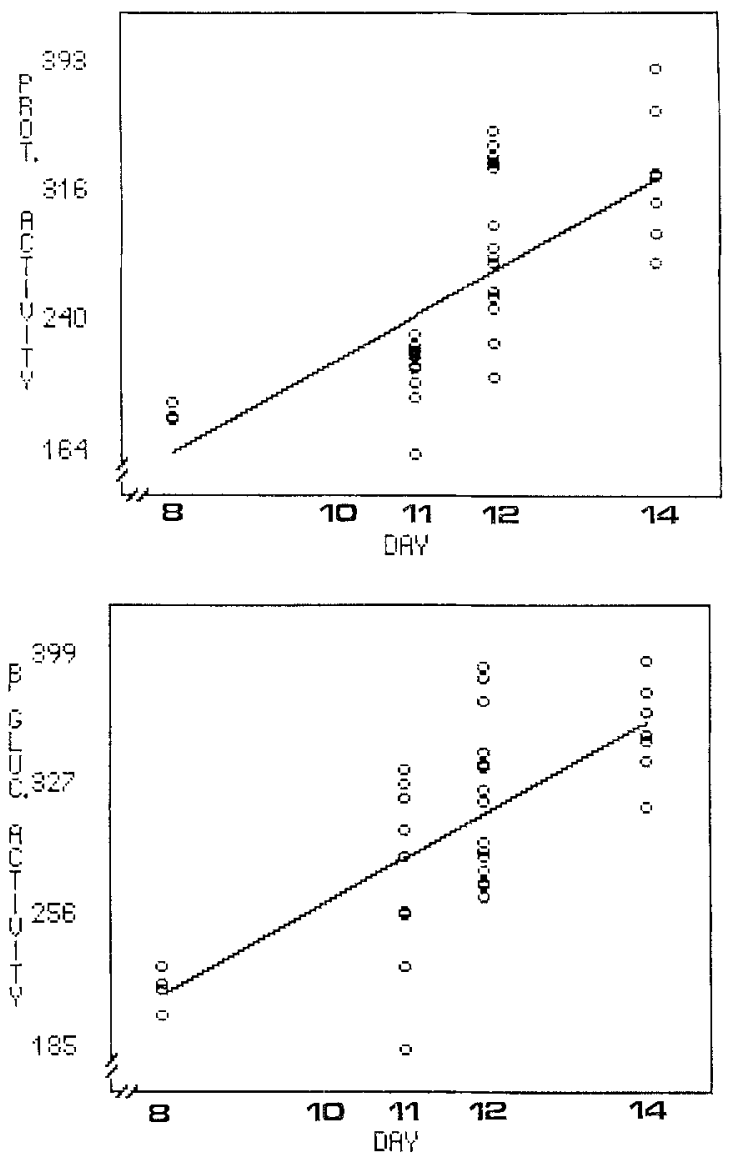

Fig. 2. Regression of the acid proteinase (a) and $\beta$-glucuronidase (b) activity on four critical days during the course of EAE. The increase of the enzyme activities show highly significant correlation with the time $(\mathrm{p}<0.001)(r=0.741$ for acid proteinase and 0.726 for $\beta$-glucuronidase).
Table II. Lysosomal Enzyme Activities During Acute EAE in Spinal Cord of Immunized Rats and Controls

\begin{tabular}{ccccc}
\hline $\begin{array}{c}\text { Day after } \\
\text { injection }\end{array}$ & 8 & 11 & 12 & 14 \\
\hline $\begin{array}{c}\text { Acid proteinase } \\
\text { EAE }\end{array}$ & $188 \pm 4$ & $214 \pm 20$ & $288 \pm 45$ & $328 \pm 40$ \\
& $\mathrm{n}=4$ & $\mathrm{n}=11$ & $\mathrm{n}=15$ & $\mathrm{n}=7$ \\
FAC & $187 \pm 28$ & $188 \pm 18$ & $185 \pm 23$ & $184 \pm 17$ \\
\% Control & $\mathrm{n}=2$ & $\mathrm{n}=8$ & $\mathrm{n}=13$ & $\mathrm{n}=6$ \\
-glucuronidase & 100 & $138^{*}$ & $156^{* *}$ & $178^{* *}$ \\
EAE & $218 \pm 11$ & $280 \pm 51$ & $313 \pm 46$ & $360 \pm 26$ \\
FAC & $\mathrm{n}=4$ & $\mathrm{n}=9$ & $\mathrm{n}=16$ & $\mathrm{n}=7$ \\
\% Control & $204 \pm 15$ & $205 \pm 20$ & $215 \pm 20$ & $232 \pm 32$ \\
$\mathrm{n}=2$ & $\mathrm{n}=6$ & $\mathrm{n}=12$ & $\mathrm{n}=6$ \\
100 & $136^{* * *}$ & $145^{* *}$ & $155^{* *}$ \\
\hline
\end{tabular}

$*: \mathrm{P}<0.01 \quad \mathrm{EAE}=$ immunized rats

** $: \mathrm{P}<0.001 \quad \mathrm{FAC}=$ Freund's adjuvant injected controls

*** : $\mathrm{P}<0.005$

Values are mean nmoles of substrate hydrolyzed/mg protein $/ \mathrm{h} \pm$ SD.

outside infiltrates. The APA found outside the perivascular cuffs was observed in cells showing glial nuclear morphology. No scattered lymphocytes or monocytes which could contribute to the APA increase were observed in these samples (Figure 5B). The APA increase outside infiltrates was detectable from the first day of the disease and no rat showed inflammatory infiltrates without a contemporary APA increase, in and outside infiltrates. On the other hand no APA increase was observed in absence of perivascular infiltrates (Table I).
Fig. 3. Regression of the acid proteinase (a) and $\beta$-glucuronidase (b) activity on the neurological symptom score of the rats with EAE. The two enzymes show an highly significant correlation $(\mathrm{p}<$ 0.001 ) with the intensity of the disease $(r$ $=0.723$ for acid proteinase and 0.782 for $\beta$-glucuronidase).
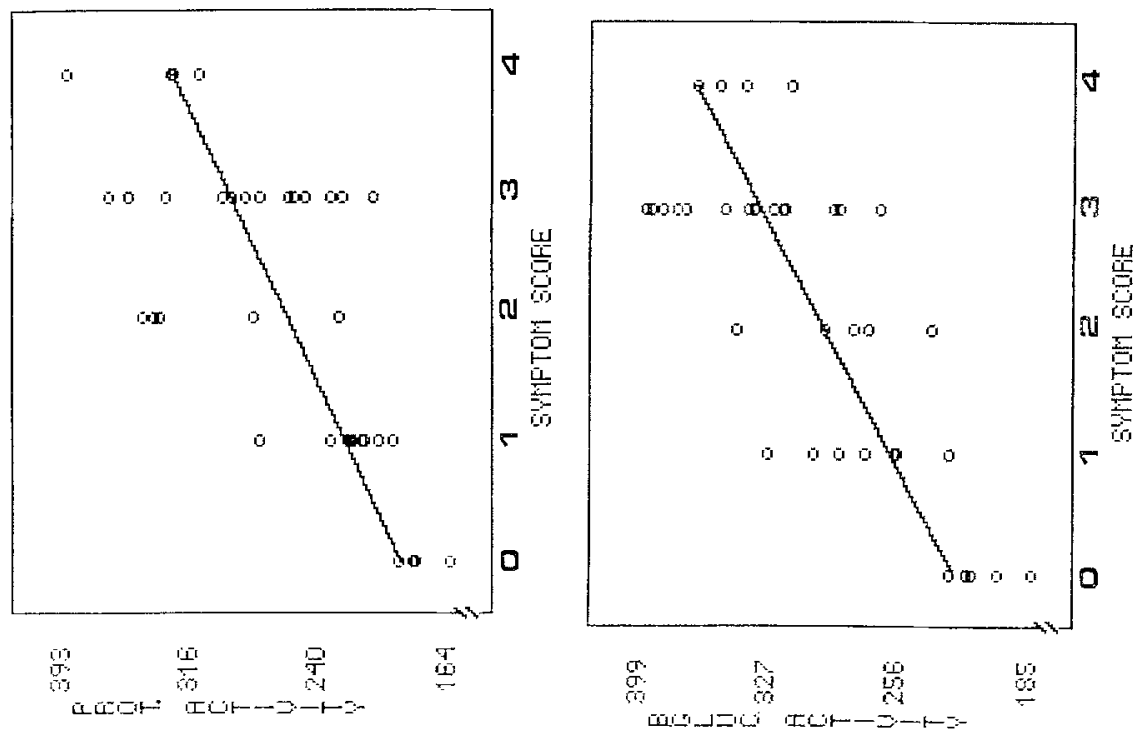


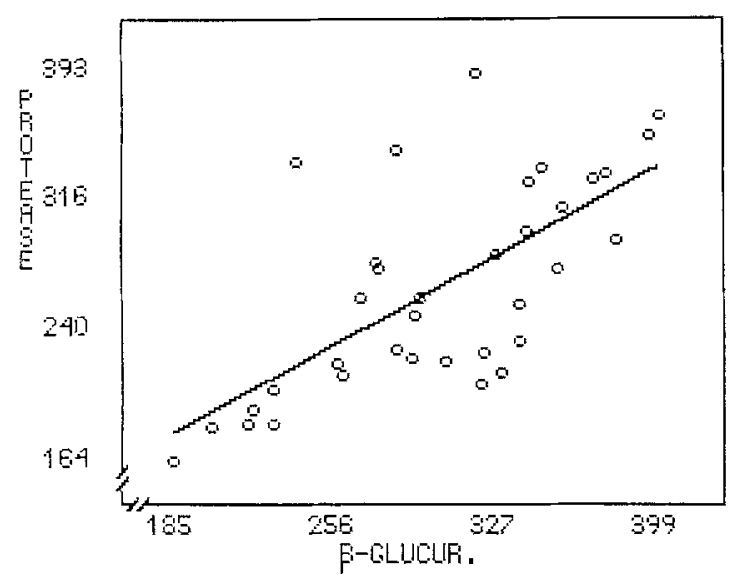

Fig. 4. Regression of the acid proteinase on the $\beta$-glucuronidase. The enzyme activity values show highly significant $(\mathrm{p}<0.001)$ correlation $(r=0.783)$

\section{DISCUSSION}

The two lysosomal enzymes chosen for this study showed a parallel increase during the course of EAE beginning from the first day of the disease. Virtually all animals which showed any neurological symptom had both APr and $\beta-G l$ increased in respect to the controls. This data confirm the increase of these and other lysosomal enzymes observed in $\operatorname{EAE}(1,2,4,5,7)$ and underline the correlation with the intensity of the disease. This observation confirms also the rationality of the proposed use of the spinal cord APr assay as parametric index of EAE (3) and indicate that another enzyme, $\beta-\mathrm{Gl}$, could be used for the same goal. Moreover, in our experience using the above described methods, $\beta-\mathrm{Gl}$ is more convenient and faster to assay than APr.

The histochemical evaluation of APA outside perivascular cuffs, showed a remarkable increase of this lysosomal enzyme activity in respect to the background APA observed in control spinal cords. This data is similar to the reported increase of APA away from infiltrates in multiple sclerosis brains, induced by astrocyte activation and proliferation (10). In this study on human nervous tissue, however, the time of the APA increase could not be determined. The present observation indicate that the APA increases from the beginning of the disease, in correspondence of the first wave of inflammatory cell infiltration in the central nervous system (CNS). The source of this early increase of lysosomal activity is attributable to cells of hematogenous origin located in the inflammatory infiltrates and to nervous cells located outside the infiltrates.
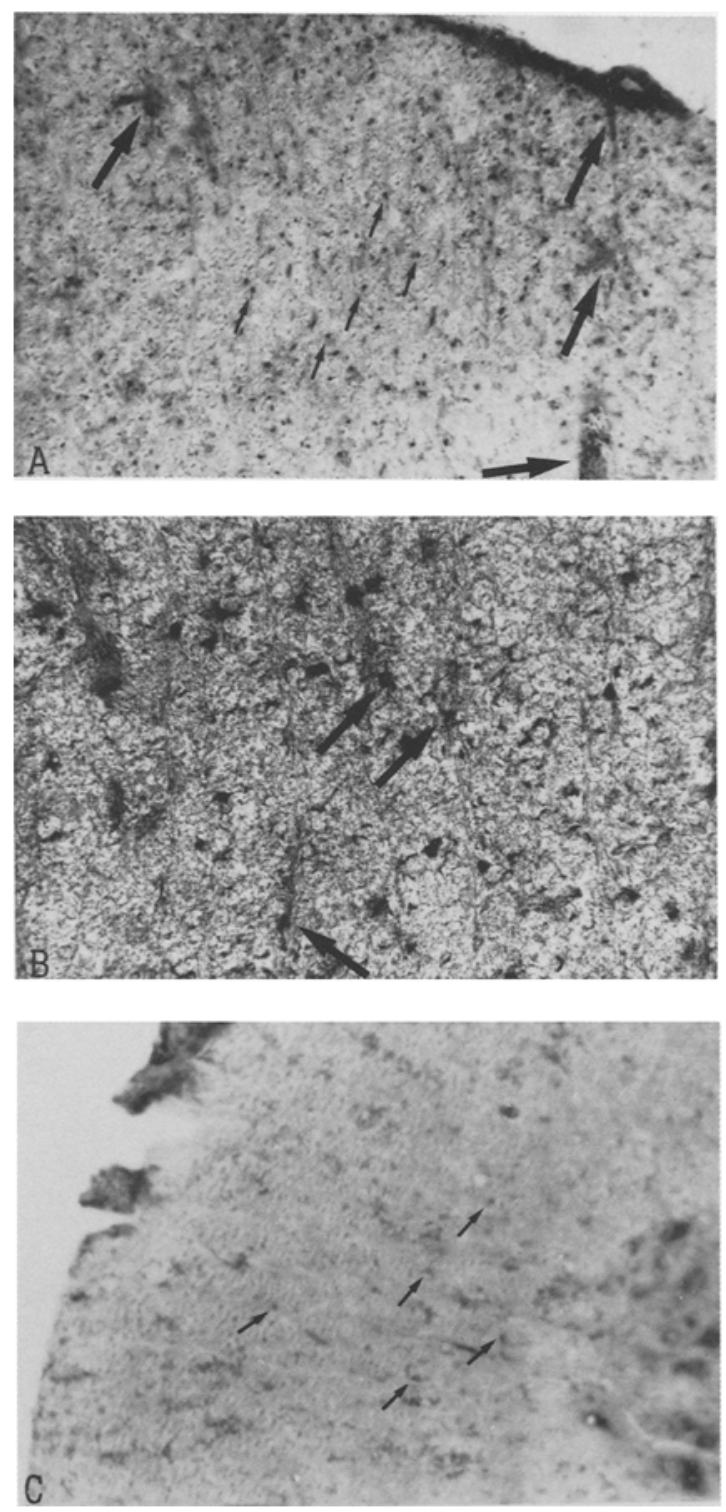

Fig. 5. Spinal cord sections from a rat with EAE at the first day of the disease (picture A and B) and a control (picture C). The sections have been histochemically stained for acid phosphatase activity (APA) and counterstained with hematoxilin to evidence the cell nucleus morphology. The APA appears as a grey area surrounding the dark cell nucleus. Clusters of inflammatory cells containing APA form perivascular infiltrates (A, large arrows) while other APA positive cells are distributed in the white matter outside the infiltrates (small arrows); the increase of the number of APA positive cells in this area of the EAE spinal cord is remarkable in respect to the background shown by the FAC sample (C). The higher magnification of the section in A (picture B), shows APA positive cells (arrows) away from the infiltrates: no inflammatory cell is detectable and the cytomorphology suggests the glial origin. 
This enzyme activity increase observed away from infiltrates, is probably a consequence of the previously described early astrocyte activation in EAE $(11,12)$. Indeed in our samples, no mononunuclear inflammatory cells scattered away from the infiltrates were observed. Edema and interleukin 1 release described during the inflammatory cell infiltration in CNS, are probably factors inducing astrocyte activation $(13,14)$. This finding does not fit with the conclusions of the Hirsch and Parkes' study, which attributed the lysosomal hydrolases increase in EAE spinal cords only to inflammatory cells of hematogenous origin (2). We believe that this interpretation is limiting and the results of that study do not exclude that autologous CNS cells can contribute to the increase of the lysosomal enzyme activity. Indeed the authors compared enzyme assays carried out in EAE spinal cords with inflammatory infiltrates, versus assays carried out in other EAE spinal cords without or with few infiltrates. No data is available in that study, from assays collected from different area (area with infiltrates versus area without infiltrates) of the same spinal cord.

The tight correlation observed between the APr and $\beta$-Gl values, suggests a causal relation with common factor(s). The perivascular cell infiltration as well as a glial reaction to the inflammatory state of the CNS tissue, are probably the factors causally related to the consensual increase of the two enzymes.

Our observations point out the increase of lysosomal enzyme activities observed in spinal cords of rats during the course of EAE and probably related to the inflammatory cell infiltrates with a contribution of endogenous CNS cells of glial origin.

\section{ACKNOWLEDGMENT}

Supported by the Italian National Research Council grant $n$. 85.00422 .56

\section{REFERENCES}

1. Smith, M. E. 1977. The role of proteolytic enzymes in demyelination in experimental allergic encephalomyelitis. Neurochem. Res. 2:233-246.

2. Hirsch, H. E., and Parks, M. E. 1975. Acid proteinases and other acid hydrolases in experimental allergic encephalomyelitis: pinpointing the source. J. Neurochem. 24:853858.

3. Smith, M. E., and Amaducci, L. 1982. Observations on the effects of protease inhibitors on the suppression of experimental allergic encephalomyelitis. Neurochem. Res. 7:541554.

4. Smith, M. E., Somera, F. P., Saldivar, R., Massacesi, L., and Trotter, J. 1984. DNA changes in spinal cords of rats with experimental allergic encephalomyelitis. J. Neurochem. 43:1635-1641.

5. Marks, N., Grynbaum, A., and Levine, S. 1977. Proteolytic enzymes in ordinary, hyperacute, monocytic and passive transfer forms of experimental allergic encephalomyelitis. Brain Res. 123:147-157.

6. Smith, M. E., Sedgewick, L. M., and Tagg, J. 1974. Proteolytic enzymes and experimental demyelination in the rat and monkey. J. Neurochem. 23:965-971.

7. Fishman, W. H. 1974. Methods of Enzymatic analysis. in Bergmeyer H.U. (ed.). Academic Press (New York).

8. Lowry, O. H., Rosebrough, N. J., Farr, A. L., and Randall, R. J. 1951. Protein measurement with the Folin phenol reagent. J. Biol. Chem. 193:265-275.

9. Barka, T. 1960. A simple azo-dye method for histochemical demonstration of acid phosphatase. Nature 187:248-249.

10. Allen, I. V. and McKeown, S. R. 1979. A histological, histochemical and biochemical study of the macroscopically normal white matter in Multiple Sclerosis. J. Neurol. Sciences 41:81-91.

11. Eng, L. F., Smith, M. E., and Gerstl, B. 1986. Glial contribution to experimental allergic encephalomyelitis. in Grisar, T., Franck, G., Hertz, L., Norton, M., Sensenbreuer, M., and Woodbury D. (eds.). Dynamic properties of glial cells. Cellular and molecular aspects. Pergamon Press (Oxford, England).

12. Smith, M. E., Somera, F. P., and Eng, L. F. 1983. Immunocytochemical staining for glial fibrillary acidic protein and the metabolism of cytoskeletal proteins in experimental allergic encephalomyelitis. Brain Res. 264:241-253.

13. Amaducci, L., Forno, K., and Eng, L. F. 1981. Glial fibrillary acidic protein in cryogenic lesions of the rat brain. Neurosci. Lett. 21:27-32.

14. Giulian, D., and Lachman, L. B. 1985. Interleukin 1 stimulation of astroglial proliferation after brain injury. Science 228:497-499. 